\title{
A trajetória dos egressos de um curso de moda: reflexões curriculares e campo de atuação
}

\section{Emanuella Scoz}

Mestranda, Fundação Universidade Regional de Blumenau/ emanuella_design@hotmail.com Orcid: 0000-0002-1651-1345 / lattes

Marcia Regina Selpa Heinzle

Doutora, Fundação Universidade Regional de Blumenau / selpamarcia@gmail.com Orcid: 0000-0002-2299-8065 / lattes

Gabriela Poltronieri Lenzi

Doutora, Fundação Universidade Regional de Blumenau / design@gabrielalenzi.com.br Orcid: 0000-0002-2758-2800 / lattes

Enviado: 19/12/2019 // Aceito: 18/02/2020 


\title{
A trajetória dos egressos de um curso de moda: reflexões curriculares e campo de atuação
}

\begin{abstract}
RESUMO
Esta pesquisa objetivou compreender a trajetória dos egressos da primeira turma do curso de moda de uma universidade pública. Com essa finalidade, analisamos as relações curriculares da formação inicial e os campos de atuação dos egressos a partir do percurso formativo. Foram analisados documentos do Projeto de Viabilidade do Curso (1996) e os questionários de egressos (2001) a partir da análise temática de Bardin (2016). Os resultados demonstram características técnicas do currículo devidas ao contexto prático vestuarista fabril regional. O percurso formativo dos egressos demonstrou atualização ao mercado de Moda com atuação em campos de trabalho intelectualizado entre o ramo de serviços, indústria e MEI.
\end{abstract}

Palavras-chave: currículo de moda. Campos de atuação. Egressos. 


\title{
The trajectory of egress in a fashion course: curriculum and professional performance
}

\begin{abstract}
This research aimed to understand the trajectory of the graduates of the first class of the fashion course of a public university. With this purpose we analyze the curriculum relations of the initial formation and the fields of action of the graduates from the formative course. Documents from the Course Feasibility Project (1996) and the graduates questionnaires (2001) were analyzed from the thematic analysis of Bardin (2016). The results demonstrate the technical characteristics of the curriculum due to the practical context of the regional industrial clothing industry. Regarding the graduation course of the graduates demonstrated update to the Fashion market acting in intellectual fields between the service industry, industry and MEI.
\end{abstract}

Keywords: fashion curriculum. Graduates. Professional performance. 


\title{
La trayectoria de los graduados de un curso de moda: reflexiones curriculares y campo de acción
}

\begin{abstract}
RESUMEN
Esta investigación tuvo como objetivo comprender la trayectoria de los graduados de la primera clase del curso de moda en una universidad pública. Para ello, analizamos las relaciones curriculares de la formación inicial y los campos de acción de los egresados del camino formativo. Se analizaron documentos del Proyecto de viabilidad del curso (1996) y cuestionarios de graduados (2001) a partir del análisis temático de Bardin (2016). Los resultados demuestran características técnicas del plan de estudios debido al contexto práctico de la fabricación regional de prendas de vestir. La trayectoria formativa de los graduados demostró una actualización del mercado de la moda con operaciones en los campos de trabajo intelectualizado entre servicios, industria y MEI.
\end{abstract}

Palabras clave: plan de estudios de moda. Campos de trabajo. Graduados. 


\section{Introdução}

Esta pesquisa teve como objetivo compreender a trajetória dos egressos que iniciaram o curso de Bacharel em moda na década de 1990 e o concluíram em 2001. A pesquisa analisou, nesse percurso formativo dos egressos, as relações curriculares da formação inicial com a atuação profissional.

A universidade escolhida como campo de pesquisa localiza-se na região sul do Brasil, numa cidade cujo contexto político e econômico foi, durante a década de 1990, perpassado pelas transformações do sistema produtivo têxtil nacional, sendo o segundo maior polo têxtil do mundo à época bem como é, ainda, segundo o IBGE (2008), uma capital de influência no país. O que nos levou a escolha do curso de Moda dessa universidade, que se manteve durante a década de 2000, assim como apontou novas perspectivas.

No contexto político, o curso foi elaborado após a LDB/1996 (BRASIL, 1996), portanto, suas escolhas culturais estariam muito ligadas aos contextos sociais locais, uma vez que a LDB/1996 (BRASIL, 1996) possibilitou flexibilizar a formação dos cursos superiores no Brasil. Em relação ao contexto econômico da década de 1990, destacam-se mudanças no mundo do trabalho. Para Antunes (2015, p. 15), essas mudanças iniciaram-se na década de 1980 em países de capitalismo avançado, repercutindo na "materialidade" e na "subjetividade" da "classe-que-vive-do-trabalho" de tal forma que a realidade do mundo do trabalho no século XXI transforma-se profundamente.

Nesse período da década de 1990, o Brasil abriu-se para os mercados internacionais e adentraram no país também os efeitos da globalização com a intensificação do desemprego e da desigualdade social, reforçando o subdesenvolvimento econômico ao compararmos o nosso desenvolvimento 
industrial nacional com 0 de nações primariamente desenvolvidas (LENZI, 2000). O estado no qual se localiza o curso em questão sentiu a entrada nos mercados internacionais por seu modelo de desenvolvimento pautado na indústria (LENZI, 2000) e com esse modelo foi inaugurada a primeira Escola de Artífices, no início do século XX.

Com a reestruturação do setor de Moda, que passou a incorporar o conceito de cultura a partir da década de 1980 (GUIMARÃES, 2008), toma fôlego, no início do século XXI, com eventos políticos que fomentaram, também, a reestruturação industrial do setor. O profissional de Moda se transformou em um profissional multitarefas no intuito de satisfazer o sistema de Moda' (SANT`ANNA, 2016).

Em 2003, a Associação Brasileira de Estilistas (ABEST) uniu esforços com a Agência Brasileira de Promoção de Exportações e Investimentos (APEX) para a internacionalização do setor têxtil e do vestuário nacional. 0 profissional de Moda, nesse contexto, adquiriu perfil multifacetado (SILVA; NASCIMENTO, 2012).

Em 2004, a Resolução n. 5, de 8 de março de 2004 (BRASIL, 2004), inseriu a Moda nas Diretrizes Curriculares do Design, sendo legitimada como campo do Design no Brasil, o que representou transformações no campo de atuação do profissional de Moda (CHRISTO; CIPINIUK, 2014). Em novembro de 2006 foi criado o Programa Cultural para o Desenvolvimento do Brasil (BRASIL, 2006), que abordava a Moda como um segmento cultural. Depois surgiram as Diretrizes do Plano Cultural da Moda, em 2013 (BRASIL, 2013), que mencionava os setores institucionais, empresariais e criativos da Moda, o que afetou o mercado de trabalho.

Ainda nesse período, a concepção de Moda foi impulsionada pelas políticas culturais para o desenvolvimento 
do Brasil (2006). Posteriormente, influenciada pelo Plano Cultural da Moda (2013), ambos alicerçaram na Moda o estudo dos hábitos de vestir, tradicionais e contemporâneos, e visavam popularizar e democratizar a Moda brasileira (BRASIL, 2013). A Associação da Indústria Têxtil e de Confecção (ABIT) participou desse processo e, a partir dele, surgem os incentivos aos pequenos e médios produtores.

Assim, ressaltamos que o contexto histórico de formação do currículo de Moda no Brasil iniciou com os currículos dos cursos técnicos, que formavam artífices para a indústria têxtil, em Santa Catarina, a partir do século XX. Para Borges e Lima (2015), o currículo do curso superior vem do currículo técnico, utilizando um conceito de Moda vinculado ao vestuário. Para Mattos (2015), por sua vez, o reducionismo do conceito de Moda no Brasil origina-se da constituição fabril do trabalho com vestuário. Assim, o surgimento dos cursos superiores no Brasil ocorre a partir da década de 1990, motivados, em partes, pela demanda do setor têxtil vestuarista, por profissionais aptos a competir no mercado externo. A partir desse breve contexto, essa pesquisa visa a compreender o currículo de Moda e suas relações com a atuação profissional do egresso.

\section{Procedimentos metodológicos}

Buscando por uma metodologia de pesquisa que abarcasse todos os contextos e atendesse ao objetivo da pesquisa, orientamo-nos pela abordagem de natureza qualitativa.

Os egressos do curso de Moda são de uma instituição pública de Santa Catarina e foi escolhida por sua representatividade política e econômica, localização, tempo de atuação e por ter sido o primeiro a ser formulado após a LDB/1996 (BRASIL, 1996) no estado. 
Quanto à geração de dados, foram realizados os seguintes procedimentos:

a) Análise de documentos: selecionamos os seguintes documentos públicos legais e curriculares que indicassem influências sobre a formação do curso de Moda: Projeto de Criação do Curso de Moda; Projeto Pedagógico do Curso (PPC), Matriz curricular do ano de 1997 e seus respectivos ementários.

b) Questionário: um questionário foi aplicado aos egressos da primeira turma do curso de Moda de uma instituição de Santa Catariana, que se formou em 2001, foram obtidos 8 respondentes dos 40 ingressantes.

O questionário foi composto em 3 blocos de perguntas. 0 primeiro teve o objetivo de caracterizar 0 perfil dos estudantes, identificando a idade de ingresso até a formação no curso de Moda, local de moradia e motivos que os levaram a ingressar no curso. O segundo bloco referia-se às ênfases curriculares do curso de Moda e ao percurso formativo dos egressos. O terceiro bloco referia-se às relações entre o currículo e o campo de atuação.

Para a análise e a interpretação dos dados gerados nessa pesquisa, escolhemos o processo descrito por Bardin (2016), que organiza uma pesquisa em três fases, a saber, a préanálise, a exploração e codificação, e a interpretação. Além disso, analisamos o currículo com base nos contextos citados por Sacristán (2000), que considera o currículo como uma construção histórico social e, portanto, complexo e carregado de simbolismos.

Sobre os dados gerados do questionário, buscamos reconhecer o percurso formativo dos egressos e seus campos de atuação. As categorias encontradas nessa fase de análise 
foram: a. motivações; b. ênfases curriculares e percurso formativo; c. contribuições do percurso formativo; $d$. formação continuada; e. campos de atuação do egresso; f. dificuldades e desafios encontrados; g. relações entre as áreas de atuação com as áreas produtivas; $h$. percurso profissional e áreas de conhecimento.

\section{Características Curriculares}

Durante a década de 1990, o setor de Moda reinventa-se em relação à:

Dimensão histórica, fenômeno midiático, o mercado editorial, a ampla cadeia produtiva, as inovações da tecnologia têxtil e dos processos de comercialização" ao mesmo tempo em que os "eventos que assumiram dimensão internacional e projetaram criadores e suas grifes para além das fronteiras nacionais (BONADIO, MARINHO, WAJNMAN, 2010, p. 2).

Os cursos de Moda tornam-se um mercado em expansão no país pela própria emancipação do capitalismo no mundo, alinhando-se aos contextos sociais vigentes. Em 1994, a "liberalização das regras de credenciamento de cursos superiores, somada ao engessamento do setor público, permitiu uma expansão sem precedentes de cursos, faculdades e universidades particulares por todo o país" (BONADIO; MARINHO; WAJNMAN, 2010, p. 3).

A LDB/1996 (BRASIL, 1996) flexibiliza a formação de cursos superiores ao indicar que estes deveriam considerar os contextos de empregabilidade locais. Assim, percebemos que o currículo do curso de Moda analisado se constituía, conforme Sacristán (2000), de um contexto prático e de um contexto teórico. 
Pautado na formação profissional para empregabilidade local, identificamos no projeto do curso de Moda analisado o interesse em formar profissionais para que as empresas têxteis locais pudessem competir globalmente em produtividade, estilo e estética, diante da abertura do mercado nacional para o internacional. Reconhecia-se o polo têxtil como principal campo de trabalho, que abrangia áreas de atuação dentro das indústrias de malha, assessoria de Moda, produção artística, indústrias têxteis, complementos para indústrias, lojas, vitrinismo, feiras, eventos e publicações.

No contexto pedagógico, nove profissionais foram contatados para fazer parte do corpo docente e lecionar os componentes profissionalizantes do curso. Em nosso estudo, identificamos que destes nove profissionais, apenas um possuía formação em Moda e os demais possuíam formação nas áreas da Engenharia têxtil e de produção, o que contribuiu para que o currículo fosse reconhecido pelos egressos em sua característica técnica.

O projeto de viabilidade do curso de Moda foi elaborado com aporte teórico de Santino Elias Gomes (1992) intitulado "O processo de criação de roupa", baseando-se no trinômio moda/vestuário/roupa, que era comum durante a década de 1990. Além disso, baseou-se também em Lipovetsky (1987), que utiliza concepções sociais de estética e consumo. 0 projeto do curso citava a dualidade entre a Moda feita em ateliês e a Moda industrializada. Os primeiros cursos superiores de Moda no Brasil foram estruturados a partir do modelo formal das escolas técnicas, proferindo um currículo de influência fabril, têxtil e do vestuário.

Na versão final da proposta curricular do curso (1997) são indicados três eixos formativos: geral, básico e profissionalizante. Esses eixos formativos foram divididos em 
duas grandes áreas: Área Comum, que engloba o eixo de formação geral e básico; e Área Específica, que contempla o eixo de formação profissionalizante, voltadas para disciplinas técnicas e teóricas de Moda.

O Quadro 1, a seguir, exemplifica a organização curricular conforme a descrição do Projeto. Pelo quadro percebemos maior carga horária dos componentes curriculares da área específica, em especial a matéria de Confecção, que abarca 7 disciplinas: Tecnologia de costura, com 120h; Tecnologia da confecção I, II, III, IV, com 240h; Modelagem industrial I e II, com 120h; Estilo I e II com 150h; Planejamento e desenvolvimento de coleção, com 60h; Normalização e qualidade industrial, com 60h; Produção de Moda com $90 \mathrm{~h}$.

Quadro 1. Estrutura curricular da Área comum e profissionalizante e suas matérias.

\begin{tabular}{|c|c|c|}
\hline & ÁREA COMUM & $\begin{array}{c}\text { ÁREA } \\
\text { PROFISSIONALIZANTE }\end{array}$ \\
\hline FORMAÇÃO GERAL & FORMAÇÃO BÁSICA & ÁREA ESPECÍFICA \\
\hline Informática $60 \mathrm{~h}$ & Administração $60 \mathrm{~h}$ & Fotografia $90 \mathrm{~h}$ \\
\hline Sociologia $60 \mathrm{~h}$ & Indumentária $120 \mathrm{~h}$ & Confecção 840h \\
\hline $\begin{array}{c}\text { Met. e técnicas de pesquisa } \\
30 \mathrm{~h}\end{array}$ & Economia $60 \mathrm{~h}$ & Desenho 300h \\
\hline Relações humanas $60 \mathrm{~h}$ & Ética 30h & Custos 60h \\
\hline Português $60 \mathrm{~h}$ & Direito $30 \mathrm{~h}$ & Mercadologia $60 \mathrm{~h}$ \\
\hline Matemática $60 \mathrm{~h}$ & Tecnologia têxtil 90h & $\begin{array}{c}\text { Estágio Supervisionado } \\
180 \mathrm{~h}\end{array}$ \\
\hline Administração $60 \mathrm{~h}$ & Cultura brasileira $60 \mathrm{~h}$ & \\
\hline Língua estrangeira $120 \mathrm{~h}$ & Fund. da linguagem $345 \mathrm{~h}$ & \\
\hline $510 \mathrm{~h} /$ aula & 795 h/aula & $1530 \mathrm{~h} /$ aula \\
\hline
\end{tabular}

Fonte: Elaborado pela autora, baseado no Projeto do curso (1996)

Em leitura minuciosa feita nas ementas de cada componente curricular que compunham as matérias descritas no Projeto, encontramos núcleos de sentido na descrição do ementário. Estes núcleos de sentido compõem as 4 categorias: a. Criação, cultura e linguagem; b. Profissional 
pleno; c. Sistema produtivo têxtil/vestuarista fabril; d. Práticas artísticas.

Conforme afirma Sacristán (2013), o currículo é formado por um contexto de prática, que considera a empregabilidade, e por um contexto teórico. Consideramos que as duas primeiras categorias fazem parte de um contexto teórico do currículo, e as categorias " $c$ " e " $d$ " fazem parte do contexto prático.

A categoria "'a" possui 8 componentes curriculares que contabilizaram 615h. Os temas tratavam de criação, cultura e linguagem, todos conhecimentos teóricos sobre Moda aplicados ao mundo do trabalho e que não tinham ligação direta com o sistema produtivo têxtil vestuarista fabril.

Outros 5 componentes curriculares compreendem conhecimentos teóricos, enalteciam as relações de trabalho em equipe, a formação humana, social e acadêmica. Estes componentes estão relacionados à categoria chamada Profissional pleno e possui $240 \mathrm{~h}$.

Considerando o contexto prático da formação profissional, encontramos em 3 componentes curriculares com temas que se concentravam nas práticas artísticas, aplicados ao mundo do trabalho, mas que não tinham relação com o sistema produtivo e também não estavam relacionadas às teorias de Moda, como "Desenho do corpo humano e pinturas manuais", categoria nomeada como Práticas artísticas e que compôs120h do currículo.

Já a categoria Sistema produtivo têxtil vestuarista fabril tinha a maior carga horária e o maior número de componentes curriculares, totalizando 1680h. Compunha-se de conhecimentos sobre sistemas e processos industriais de produção aplicados ao mundo do trabalho. Os componentes curriculares tinham aplicação no sistema produtivo têxtil vestuarista, a saber, processos industriais, produção 
industrial, maquinário industrial, gestão de equipes visando a eficácia e eficiência dos processos fabris, e gestão de produto no sistema produtivo, desenho com uso de softwares e ferramentas apropriadas ao sistema industrial, tecnologias de maquinários e processos produtivos, e demais práticas que visavam, especificadamente, os processos de produção fabris.

O Projeto de viabilidade do curso (1996) incorporava, ainda, a reformulação industrial que ocorria no Brasil e anunciava o futuro do desenvolvimento da região pela indústria do têxtil e do vestuário, que era vasta e fazia parte da cultura regional e que estiveram presentes nos eixos formativos do currículo divididos em formação básica e profissionalizante. Isso demonstra a presença massiva de conhecimentos técnicos para a produção têxtil pautando-se num modelo econômico que investia na industrialização para o desenvolvimento.

\section{Percurso formativo e trajetória profissional dos egressos}

Ao analisarmos o perfil dos participantes dessa pesquisa, identificamos que ingressaram no curso com idades entre 18 e 29 anos e o concluíram no prazo médio de 4 anos.

Ao serem questionados sobre quais as motivações que os levaram a escolher o Curso de Moda, as principais razões apontadas foram: a. Ingressar em áreas não produtivas; $b$. Pioneirismo e ineditismo do curso; c. Inserção no setor de Moda existente ou desejada. Os egressos demonstram também o interesse em áreas de atuação do Jornalismo e Artes e atividades criativas, que foram relacionadas ao curso de Moda pelos egressos.

Em relação à ênfase da formação no Curso de Moda, todos os egressos participantes do questionário relacionaram que a 
formação estava voltada para as questões de produtividade (técnica) e gestão e justificam a escolha do curso por: a. contexto pedagógico; b. foco industrial; e c. mercado e empregabilidade.

Os excertos da pesquisa trazem indicações dos egressos como: "grade curricular composta majoritariamente por disciplinas técnicas" (EGRESSO 1), "professores que se destacavam eram os técnicos" (EGRESSO 2), "foco na indústria" (EGRESSO 3) e "Produção em massa é o foco e não o lançamento de Moda" "Por estarmos num polo têxtil, grande gerador de renda e onde a produção em massa é o foco e não o lançamento de Moda (não somos uma cidade que dita a Moda, nós a seguimosii), faz-se necessário o conhecimento mais técnico, para gerar ganhos de produtividade, redução de custos e melhores métodos de trabalho dentro dessa indústria" (EGRESSO 4).

A fala do egresso 4 nos permite compreender o conceito de Moda empregado na região e observamos a sua inserção como um fator de inovação que permitiu o reposicionamento das indústrias locais nos mercados com ganho de eficiência ao abranger o ensino da gestão e produção. A indústria visava o prazo, o custo e a qualidade e começava um processo de agregar valor estilístico. Dar estilo aos produtos serviria como fator de inovação, mantendo a competitividade no mercado global.

Foi no século XXI que a organização do setor de Moda nacional concretizou um conceito mais amplo de Moda. O Plano Cultural da Moda (2013) tinha diretrizes para o setor acadêmico, que tratava das cadeias produtivas, iniciativas culturais, mídias impressas e digitais, observatório de Moda, internacionalização e premiações, dentre outros, e diretrizes para os setores institucional, criativo e empresarial, visando institucionalizar a Moda no Ministério da Cultura. 
Estes dados formularam o Plano Cultural da Moda, em 2013, no entanto, vinham sendo discutidos no setor desde o início da década de 2000 com o Projeto Cultural para o desenvolvimento do Brasil (2006). O país vinha explorando sua Moda com identidade nacional em eventos como o São Paulo Fashion Week, que teve sua primeira edição em 1994, e tomava visibilidade internacional no século XXI.

Para os egressos, o currículo analisado contribuiu para a formação profissional e pessoal, tanto no campo prático quanto no campo teórico. Como sugestão de melhoria, os egressos indicaram $\mathrm{o}$ aprendizado por projetos e 0 direcionamento do curso em áreas de atuação, podendo o estudante escolher áreas de interesse profissional.

Segundo Sacristán (2000, p. 37), "no ensino universitário se destaca a adequação dos currículos ao progresso da ciência, de diversos âmbitos do conhecimento e da cultura, e à exigência do mundo profissional". A nova morfologia do mundo do trabalho considera a totalidade do trabalho social (ANTUNES, 1995) e o surgimento de novos arranjos produtivos de trabalho em nível global, o que torna complexa a estruturação curricular na formação inicial.

Como sugestões levantadas pelos egressos (2001) percebemos componentes curriculares para um novo mundo do trabalho, como: mídias sociais, e-business, intercâmbios profissionais, matéria gráfico, negócios da Moda, relações entre a indumentária e as ciências humanas e comunicação. Muitos deles surgiram no Brasil apenas a partir do século XXI e possibilitam identificar a relação global dos campos e atuação da Moda. Dessa forma, observamos que o perfil profissional migrou não de forma a trocar o conhecimento técnico, mas de forma a somar os conhecimentos teóricos e práticos já existentes sobre Moda às morfologias do mundo do trabalho. 
Os egressos relataram ter efetuado cursos de formação complementar em áreas ligadas à criação de Moda, Modelagem, Desenho, Desenvolvimento de coleção, Gestão, Pesquisa e docência, Marketing e Tendências de comportamento, que coincidiram com os campos de atuação por eles descritos, como Consultoria de Moda e estilo, Desenvolvimento de produtos, Gestão de marcas, Equipes e produtos, docência, pesquisa acadêmica, Marketing e vendas, Produção de eventos e Modelagem.

Nos cursos descritos pelos egressos, percebemos que eles tinham foco diferente da indústria, muitos realizados em Institutos internacionais, como Moda Burgo, em Milão, e Modelagem, com Marie Rucki, em Paris, e, ainda, o Fashion International Technology (FIT), em Nova Iorque.

Em relação aos campos de atuação acessados pelos egressos, 4 respondentes identificaram contatos com áreas produtivas em nível local, 2 em regional e 3 em nacional e internacional, sendo que um egresso identificou não ter tido, em sua trajetória profissional, contato com áreas produtivas. Da mesma forma, 4 respondentes identificaram contato profissional com áreas criativas, sem relação com processos produtivos, em nível local, 2 em nível regional e 3 em nível nacional e internacional. Isso nos revela as relações em níveis locais, nacionais, regionais e globais, tanto produtivas quanto criativas.

Os campos de atuação acessados pelos egressos estavam integrados às indústrias em $43 \%$ dos casos e, igualmente, em $43 \%$ ao setor de serviços e $17 \%$ dos respondentes tornaramse Microempreendedores Individuais (MEI).

O acesso aos diferentes arranjos produtivos ainda nos ajudou a questionar em que segmentos de mercado os egressos mantiveram suas experiências profissionais. Deste modo, perguntamos se essas empresas em que trabalham ou 
trabalharam por mais tempo são caracterizadas como marca própria, magazines ou private label. Dos 7 respondentes, 4 responderam marcas próprias, 3 private label e 1 magazines. Podemos concluir que a maior parte dos respondentes fez ou faz parte de indústrias de marcas próprias.

Os magazines, segmento da Moda que teve crescimento durante o início do século XXI, vendem marcas próprias, as quais detêm o direito autoral da marca ou produtos, mas terceirizam a produção para diversas MPE, ou compram de grandes produtores, pois se caracterizam no ramo da Moda chamado fast fashion, que exige grande volume de vendas e troca de produtos mensais. Normalmente, as marcas que são vendidas em magazines terceirizam o processo criativo para escritórios independentes, bem como utilizam um sistema produtivo terceirizado.

Percebemos, por todas essas relações, um meio fértil da economia têxtil com diversificação de segmentos produtivos, econômicos e abertos às novas estruturas de trabalho e arranjos produtivos. Esses registros demonstram a existência de uma economia complexa, alinhada ao modelo econômico global. Isso também nos demonstra que há um relacionamento produtivo concomitante ao relacionamento específico da área da Moda com pesquisa, desenvolvimento, produção de Moda e produção visual ligado à indústria cultural.

Deste modo, estes dados nos levam a crer que houve um desenvolvimento gradativo e homogêneo dos negócios da Moda na região, além de campos de atuação com relacionamento em nível local, nacional, regional ou internacional com redes de relações criativas e produtivas diversificada.

Perguntamos aos respondentes se relacionavam seu percurso profissional com a Moda na área de produção e 
gestão ou voltada para a cultura, produção cultural e indústria cultural. Como resultado, $85,7 \%$ dos respondentes relacionam seu percurso profissional com a Moda na área da produção e gestão. Já 28,6\% o relacionam com a área da cultura, produção cultural e indústria cultural durante seu percurso profissional. Em sua trajetória profissional, os egressos reconheceram um campo prático focado em processos produtivos.

A trajetória profissional dos egressos que responderam ao nosso questionário nos mostra a experimentação pelas áreas e atuação em serviços, Microempreendedor Individual (MEI), varejo e em educação, demonstrando a ramificação e a diversidade dos campos de atuação em Moda. A partir destes relatos compreendemos que não há como pensar em um curso de Moda que se constitua apenas de uma ou outra organização de conhecimento ou ênfase curricular.

$\mathrm{Na}$ análise da trajetória profissional e formativa dos egressos, percebemos a ocorrência das transformações no mundo do trabalho, a exemplo dos desafios de um mundo de conhecimentos mundializados, transnacionalizados e internacionalizados (ANTUNES, 2015). Os países cujo foco de progresso era industrial, como o Brasil, tinham, ao final do século $\mathrm{XX}$, "um significativo desenvolvimento tecnológico [...] desconcentração produtiva baseada em empresas médias e pequenas, artesanais" (ANTUNES, 1995, p. 17).

\section{Relações estabelecidas entre os campos de atuação e a formação inicial}

Essa nossa análise dos dados tem como objetivo estabelecer relações entre os campos de atuação dos egressos do ano de 1997 e a sua formação inicial. Observamos relações de proximidade entre os campos de 
atuação: industrial, do contexto têxtil vestuarista e em desenvolvimento de coleção.

Entretanto, identificamos distanciamento da formação inicial com setores de: produção artística e indústria de complementos. Verificamos também a relação de isolamento com campos de atuação do Desenho criativo para estamparia e da Pesquisa científica, o que significa que estes campos de atuação foram acessados pelos egressos, mas consideram que o currículo, embora tenha sido válido para sua formação profissional, não auxiliou no ingresso nestes campos de atuação.

Vale ressaltar que o Projeto do curso previa a formação para atuação em confecção de roupas de cama, mesa e banho, malharias e tecelagens, estamparia, assessoria de Moda, Produção artística, Indústria de complementos e aviamentos, Academia e Comunicação de Moda na produção e participação de eventos, vitrines, lojas e demais veículos.

$\mathrm{Na}$ trajetória profissional dos egressos que participaram desta pesquisa não foram encontradas relações entre a produção artística de Moda e a indústria de complementos. A produção artística regional ao curso ora analisado possui uma diversidade maior em pequenas empresas de produção artística para teatro, televisão, dança, cinema, jornalismo, circo e comunicação.

Em relação à cidade em que a universidade é localizada, há 244 agentes de cultura cadastrados e 9 espaços específicos das áreas listadas que possibilitariam a atuação com produção de Moda, Styling, Fotografia, Artes gráficas e digitais, Pesquisa, Desenvolvimento e produção de figurino dentre outras. Nenhum destes campos de atuação foi citado pelos egressos respondentes.

Observamos ainda, por meio do relato dos egressos, que os campos de atuação existentes eram essencialmente fabris. 
Foram relatadas dificuldades, por exemplo, no acesso aos campos de atuação criativos, o que nos faz entender que estes agentes e espaços criativos cadastrados na plataforma da cidade são recentes e, portanto, não fazem parte até o momento do percurso profissional dos egressos.

Tanto nos campos de atuação acessados como na formação complementar houve variedade de temas estudados, no entanto, a atuação em desenvolvimento de coleção foi um ponto em comum para maior parte dos egressos, permanecendo isolados os campos de atuação de desenvolvimento de estamparia e a pesquisa científica e docência.

Além disso, a trajetória formativa e profissional dos egressos de 2001 demonstrou-se internacionalizada e diversificada. Entendemos, assim, que as relações profissionais e formativas construídas pelos egressos em seus campos de atuação, depois da formação inicial, ultrapassaram fronteiras geográficas, uma vez que atuaram na região do Vale do Itajaí, Curitiba, São Paulo e, internacionalmente, em Milão, Paris e Nova Iorque. Todos esses lugares participam da economia criativa de Moda, assim como de clusters têxteis.

\section{Considerações finais}

Ao iniciar esta pesquisa, buscávamos compreender a trajetória dos egressos que iniciaram o curso de Moda na década de 1990 e que o concluíram em 2001, assim como as relações curriculares da formação inicial com a atuação profissional. Ao fim desta pesquisa concluímos que as escolhas curriculares deste curso de Moda foram perpassadas por contextos e instâncias reguladoras, no sentido do termo que cita Sacristán (2000), em que vigoraram contextos 
pedagógicos de características técnicas. Mantendo relação estreita com o setor têxtil e de Moda do Vale do Itajaí, sem, no entanto, aplicar a formação de um profissional multifacetado, característico do setor.

A caracterização curricular nos permitiu perceber que 0 currículo estava alinhado às demandas profissionais do setor industriário local, com maior ênfase no sistema produtivo têxtil/vestuarista fabril seguido por ênfase na criação, cultura e linguagem de Moda.

O currículo do curso de Moda teve como contexto histórico as políticas de colonização e desenvolvimento do Estado em que se encontra, assim como teve influências do conceito de Moda vestuarista vivido no Brasil, das políticas educacionais da década de 1990, das políticas econômicas e da globalização. Nesse período de construção do projeto foi identificada a falta de profissionais formados em Moda com titulação necessária para preencher o quadro de professores do curso como uma das exigências reguladoras.

As relações construídas pelos egressos a partir do currículo de formação inicial em seus campos de atuação foram muito próximas. No entanto, a diversificação dos arranjos produtivos e modelos de negócios, durante o século XXI, trouxeram aos egressos a necessidade de formação complementar em setores da Moda relacionados com sistemas produtivos diferenciados, bem como em outros setores como Marketing, Pesquisa científica, Comunicação e Criatividade.

Durante a trajetória dos egressos, o sistema capital seguiu suas transformações adentrando em economias semiperiféricas e fomentando as morfologias do mundo do trabalho. A corrida pela profissionalização para o setor industrial foi uma forma de acompanhar as nações primariamente industrializadas. Nesse contexto, vimos 
emergir, das morfologias do mundo do trabalho, a diversidade de campos de atuação e, dessa diversidade, entendemos a dificuldade de garantir formação curricular para os cursos de Moda, que costumam orientar-se por demandas profissionais locais.

$\mathrm{Na}$ análise da proposta curricular, percebemos que os autores do Projeto de criação do curso fizeram escolhas culturais que envolveram o contexto da prática e o contexto teórico. O contexto teórico escolhido para o curso foi a abordagem vestuarista da Moda, conceito comum no século XX, conforme aborda Trevisol Neto (2015). Este se aplicou ao contexto prático existente, satisfazendo as demandas profissionais da indústria têxtil vestuarista da região.

Ainda na relação do percurso formativo dos egressos, foi sugerida a inserção de intercâmbios interacionais, o que indica a necessidade de um currículo internacionalizado. Durante a trajetória profissional, alguns egressos tiveram oportunidades de trabalhar fora do Brasil, bem como os que permaneceram no país, mantiveram contatos internacionais em suas atividades profissionais. Também foi sugestão dos próprios egressos para a formulação curricular e pedagógica do curso de Moda, o ensino por projetos, o que envolve todos os componentes curriculares. Outra possibilidade apontada seria a escolha por setores de atuação no segundo ano do curso, seguindo para um uma área do sistema de Moda, de forma a suprir as demandas profissionais das economias complexas.

Assim sendo, os dados gerados nos possibilitaram compreender o currículo de um curso de Moda e suas relações com os campos de atuação do profissional egresso. No entanto, para que seja possível repensar o currículo baseando-o nos contextos teóricos e práticos existentes, dada a diversidade do setor, são necessárias mais pesquisas sobre 
os campos de atuação dos profissionais de Moda no Brasil, dando voz aos egressos, de forma que eles auxiliem na formulação curricular.

\section{REFERÊNCIAS}

ANTUNES, Ricardo. Adeus ao trabalho? Ensaio sobre as metamorfoses e a centralidade do mundo do trabalho. 3. ed. São Paulo: Cortez, 1995.

ANTUNES, Ricardo. Adeus ao trabalho? Ensaio sobre as metamorfoses e a centralidade do mundo do trabalho. 16. ed. São Paulo: Cortez, 2015.

BONADIO, Maria Claudia; MARINHO, Maria Gabriela, WAJNMAN, Solange. Apresentação - Dossiê Moda e conhecimento: interfaces com as ciências humanas e a comunicação. Iara, v. 3, n. 3, 2010. Disponível em: http://www1.sp.senac.br/hotsites/blogs/revistaiara/index.php/vol3-no3-ano-2010/. Acesso em: 17 dez. 2019.

BRASIL. Presidência da República, Casa Civil. Lei no 9.394, de 20 de dezembro de 1996. Estabelece as diretrizes e bases da educação nacional. Brasília, 20 dez. 1996. Disponível em: http://www.planalto.gov.br/ccivil_03/LEIS/L9394.htm. Acesso em: 16 dez. 2019.

BRASIL. Ministério da Educação. CNE. Resolução n. 5, de 8 de março de 2004. Brasília, 8 mar. 2004. Disponível em: http://portal.mec.gov.br/cne/arquivos/pdf/rces05_04.pdf. Acesso em: 09 set. 2019.

BRASIL. Ministério da Cultura. Programa Cultural para o Desenvolvimento do Brasil. Brasília: MinC, 2006. Disponível em: http://rubi.casaruibarbosa.gov.br/bitstream/20.500.11997/6837/1 /119.pdf. Acesso em: 17 dez. 2019.

BRASIL. Ministério da Cultura. Plano Cultural da Moda. Brasília: Ismália Afonso, SPC/MinC, 2013. Disponível em: https://bit.ly/2PdCzkh. Acesso em: 17 dez. 2019.

CHRISTO, Deborah Chagas. CIPINIUK, Alberto. Estilista? Designer de Moda...ou um Designer de objetos do vestuário? Dobras, v. 7, n. 15, p. 13-22, 2014. Disponível em: https://dobras.emnuvens.com.br/dobras/article/view/69/69.

Acesso em: 17 dez. 2019.

GUIMARÃES, Maria Eduarda Araújo. Moda, Cultura e identidades. In: ENECULT- ENCONTRO DE ESTUDOS MULTIDISCIPLINARES EM CULTURA, 4, 2008, Salvador. Anais [...]. UFBA: Salvador, 2008. Disponível em: http://www.cult.ufba.br/enecult2008/14326.pdf. Acesso em: 17 dez. 2019.

LENZI, Cristiano Luís. 0 "Modelo Catarinense" de desenvolvimento: uma ideia em mutação? Blumenau: Edifurb, 2000. 
MATTOS, Maria de Fátima da Silva Costa Garcia. (Org.) Pesquisa e formação em Moda. São Paulo: Estação das Cores e Letras, 2015.

SACRISTÁN, José Gimeno. o currículo. Uma reflexão sobre a prática. Tradução de Ernani F. da Fonseca Rosa. 3. ed. Porto Alegre: Artmed, 2000.

SANCHES, Lucinéia. Os moldes da moda: um estudo sobre o estado dos cursos de formação em Moda no Brasil. 2006. $121 \mathrm{f}$. Dissertação (Mestrado em Educação) - Universidade Regional de Blumenau, Blumenau, 2006.

SANT'ANNA, Mara Rúbia. Teoria da Moda - Sociedade, Imagem e Consumo. 2. ed. São Paulo: Estação das letras e cores, 2016.

SILVA, Barbará Cravo da. NASCIMENTO, Luís Cláudio Portugal. Apontamentos acerca da integração entre conteúdos de Design e de Moda no percurso de implementação do Design de Moda. Projética, Londrina, v. 3, n. 1, p. 110-118, 2012. Disponível em: http://www.uel.br/revistas/uel/index.php/projetica/article/view/12 266/11334. Acesso em: 17 dez. 2019.

TREVISOL NETO, Orestes. A institucionalização científica do campo da Moda no Brasil: estudo baseado nas instituições, produtores e produtos científicos. 2015. 191 f. Dissertação (Mestrado em Ciência da Informação) - Universidade Federal de Santa Catarina, Florianópolis, 2015. Disponível em: https://repositorio.ufsc.br/xmlui/bitstream/handle/123456789/135 394/334677.pdf?sequence=1\&isAllowed=y. Acesso em: $17 \mathrm{dez}$. 2019. 